\title{
Impact of perovskite precursor solution temperature on charge carrier dynamics and photovoltaic performance of perovskite based solar cells
}

Gon Namkoong*, ${ }^{*}$, Abdullah A. Mamun ${ }^{1}$, Tanzila Tasnim Ava ${ }^{1}$, Kai Zhang ${ }^{1}$, and Helmut Baumgart ${ }^{1}$.

${ }^{1}$ Department of Electrical and Computer Engineering, Old Dominion University, Applied Research Center, 12050 Jefferson Ave, Newport News, VA 23606, USA

*Corresponding author: gnamkoon@odu.edu

\begin{abstract}
Even though perovskite based solar cells have been routinely fabricated with preheated perovskite solutions, currently the underlying mechanism of how the perovskite precursor solution temperature influences perovskite solar cells has not been studied yet. Therefore, we investigated the impacts of perovskite solution temperatures on charge carrier dynamics of perovskite film and perovskite solar cell performance that were quantitatively analysed using steady-state photoluminescence (PL), time-resolved emission spectra (TRES), excitation-dependence of PL and current-voltage measurements. It is found that the perovskite solution temperature greatly influenced the morphologies, defect densities and states, and charge recombination dynamics of perovskite thin films. Particularly, steady-state and time-resoled PL measurements revealed that perovskite thin films prepared with the perovskite solution temperature around $70{ }^{\circ} \mathrm{C}$ produced lowest surface and bulk defect densities. In addition, it is found that the perovskite solution temperature around $70^{\circ} \mathrm{C}$ led to exciton-like transitions while lower
\end{abstract}


and higher solution temperatures led to defect-mediated recombination of perovskite thin films. Such recombination dynamics of perovskite films strongly influenced the light absorption and extraction efficiencies of photogenerated charge carriers which in turn influenced short-circuit current, fill factor, and open circuit voltage of perovskite solar cells. As a result, better photovoltaic performance of perovskite solar cells was observed when prepared with the precursor temperature around $70^{\circ} \mathrm{C}$.

Keywords: perovskites; photoluminescence; time-resolved emission spectra; exciton-like transitions; defect-mediated recombination 


\section{Introduction}

Hybrid halide perovskite material family has revolutionized the prospects of next-generation photovoltaics, demonstrating higher energy conversion efficiency over the past few years $[1,2,3,4]$. From a chemical point of view, perovskite materials are composed of complicated chemical structure in the $\mathrm{ABX}_{3}$ coordination [5], in which the A cations are organic, typically composed of $\mathrm{CH}_{3} \mathrm{NH}_{3}{ }^{+}$(or $\mathrm{MA}^{+}$), the $\mathrm{B}$ metal cations are divalent metal ions such as $\mathrm{Pb}^{2+}, \mathrm{Sn}^{2+}$ while the $\mathrm{X}$ anions are halides including $\mathrm{Cl}^{-}, \mathrm{Br}^{-}$, and $\mathrm{I}^{-}$. Among them, $\mathrm{CH}_{3} \mathrm{NH}_{3} \mathrm{PbI}_{3-\mathrm{x}} \mathrm{Cl}_{\mathrm{x}}$ $\left(\mathrm{MAPbI}_{3-\mathrm{x}} \mathrm{Cl}_{\mathrm{x}}\right)$ has been widely investigated for solar cell applications due to exceptional optical and electrical properties including a direct band gap, a large absorption coefficient and very high charge carrier mobility [6]. However, one of the main challenges is to produce pin-hole free morphologies with larger grains during the deposition and crystallization of the perovskite layer $[7,8]$. This is because a uniform surface coverage of the perovskite film is crucial for solar cells to avoid shunting [7] and the notorious hysteresis effects [8]. For perovskite films, sequential deposition $[9,10]$ or spin-coating methods [11] have been widely used and typically resulted in smaller grain size of $1 \sim 2 \mu \mathrm{m}$ with many pin-holes. In contrast, a hot casting technique [8] facilitates the thermal energy to form larger grain of the perovskite during the spin-casting process, in which the glass slide is heated at near or higher temperature than the boiling temperature of dimethylformamide (DMF) solvent $\left(153^{\circ} \mathrm{C}\right)$. Particularly, processing conditions play critical roles in crystallinity control and morphology formation of perovskite thin films for achieving higher photovoltaic performance [12]. For instance, processing conditions such as spin speeds, thermal annealing, precursor ratios, etc. are crucial as they determine the crystallinity, size, and orientation as well as the film morphology of perovskite films. Interestingly, the higher efficiency of perovskite solar cells was achieved with perovskite precursor solutions prepared at 
the temperature of $70{ }^{\circ} \mathrm{C}[13,14]$. Surprisingly, even though such impacts on perovskite solar cells have been studied, there is no account about why the perovskite precursor solution temperature should be around $70{ }^{\circ} \mathrm{C}$. In addition, there is no systematic study regarding charge carrier dynamics of perovskite films prepared with different precursor solution temperatures and their impacts on the final device performance. In this study, we investigate the effect of perovskite precursor temperatures on charge carrier dynamics of perovskite films and performance of perovskite solar cells prepared with different precursor temperatures from room temperature to $90{ }^{\circ} \mathrm{C}$. To perform this investigation, we used steady-state and time-resolved photoluminescence (PL), time-resolved emission spectra (TRES), excitation-dependence of PL and current-voltage measurements.

\section{Experimental details}

2.1. Fabrication of perovskite thin films and perovskite solar cells with different perovskite solution temperature

Perovskite $\left(\mathrm{CH}_{3} \mathrm{NH}_{3} \mathrm{PbI}_{3-\mathrm{x}} \mathrm{Cl}_{\mathrm{x}}\right)$ films were prepared using a hot-casting technique. Perovskite $\left(\mathrm{CH}_{3} \mathrm{NH}_{3} \mathrm{PbI}_{3-\mathrm{x}} \mathrm{Cl}_{\mathrm{x}}\right)$ solution was prepared by dissolving equimolar ratios of lead iodide $\left(\mathrm{PbI}_{2}\right.$, Sigma-Aldrich, 99\%) and methylamine hydrochloride (MACl, Sigma-Aldrich) in N, Ndimethylformamide (DMF, Sigma-Aldrich, anhydrous, 99.8\%) in $11 \mathrm{wt} \%$ concentration. The perovskite solutions were ready for use after heating in a hot plate at different temperatures of 40 , 70 and $90{ }^{\circ} \mathrm{C}$ for $24 \mathrm{~h}$ with magnetic stirring in a $\mathrm{N}_{2}$ filled glove box. FTO/glass substrates were cleaned with four times sonication (each for 10 minutes) in de-ionized (DI) water, methanol, acetone, and 2-propanol (IPA), respectively. Afterwards, the substrates were dried with nitrogen,

followed by heating in a hot plate at $120{ }^{\circ} \mathrm{C}$ for 15 minutes to remove the last traces of any 
solvent. For optical characterization, perovskite solutions heated at different solution temperatures of 40,70 and $90{ }^{\circ} \mathrm{C}$ were spin-coated on glass slides preheated at $180{ }^{\circ} \mathrm{C}$. For perovskite solar cells, PEDOT:PSS diluted by using 2-propanol in a ratio of 1:3 was spin coated on FTO/glass substrates at a speed of $3000 \mathrm{rpm}$. In addition, perovskite thin films were prepared on preheated PEDOT:PSS/FTO/glass at $180{ }^{\circ} \mathrm{C}$ with perovskite solutions heated at different solution temperatures of 40,70 and $90^{\circ} \mathrm{C}$. The electron transport layer consists of PCBM(Nano-c) dissolved in di-chlorobenzene(Sigma-Aldrich) that was spin coated on the top of perovskite layer at a speed of $1500 \mathrm{rpm}$ in a $\mathrm{N}_{2}$ containing glove box. Silver was deposited by using electron beam evaporation. Therefore, the resultant perovskite solar cells consisted of FTO/PEDOT:PSS/MAPbI ${ }_{3-\mathrm{x}} \mathrm{Cl}_{\mathrm{x}} / \mathrm{PCBM} / \mathrm{Ag}$. Scanning electron microscope (SEM) results showed that the thickness of the perovskite layer depended on the perovskite solution temperature and was $210 \pm 8 \mathrm{~nm}, 252 \pm 7 \mathrm{~nm}$ and $270 \pm 6 \mathrm{~nm}$ at perovskite solution temperatures of 40,70 and $90^{\circ} \mathrm{C}$. In addition, the thickness of PEDOT:PSS and PCBM layers was measured to be about tens of nanometers and $\mathrm{Ag}$ metal was measured to be about $180 \mathrm{~nm}$.

\subsection{Characterization}

Steady-state and time-resolved photoluminescence (PL) measurements were performed using Horiba FluoroLog-3 spectrofluorometer and time-correlated single photon counting (TCSPC) with a solid-state laser with $450 \mathrm{~nm}$, which was used for the various excitation intensities. Both a continuous $450 \mathrm{~W}$ xenon lamp and pulsed laser-diode were used to measure steady-state PL and lifetime decays. Particularly, the TCSPC is fiber-coupled into Olympus BX53F microscope equipped with a CCD camera capable of measuring PL and lifetime mappings while showing microscopic morphologies. To record photoluminescence (PL), perovskite samples were coated 
with PMMA to prevent degradation from air environment. The UV-VIS spectra were measured by using Perkin Elmer Lambda 45 spectrophotometer. To measure UV-VIS, active layer of perovskite was prepared on top of a glass substrate. The current-voltage (I-V) characteristics were recorded in ambient air by using Keithley 2400 under AM1.5 condition $\left(100 \mathrm{~mW} / \mathrm{cm}^{2}\right)$ of a solar simulator (Newport 69907).

\section{Results and discussion}

Fig. 1 shows the morphologies and optical properties of $\mathrm{MAPbI}_{3-\mathrm{x}} \mathrm{Cl}_{\mathrm{x}}$ films spin-casted with different precursor temperatures. When the perovskite solution heated at $40{ }^{\circ} \mathrm{C}$ was spin-casted, smaller grains of tens of micrometres were obtained as shown in Fig. 1(a). In contrast, much larger grains were obtained with higher solution temperatures of $70^{\circ} \mathrm{C}$, as shown in Fig. 1 (b) while a further increase in solution temperatures to $90{ }^{\circ} \mathrm{C}$ resulted in decreased grain sizes in Fig. 1(c). Another interesting observation is the blueshift of photoluminescence (PL) spectra. Remarkably, when the perovskite films were prepared with lower $\left(40{ }^{\circ} \mathrm{C}\right)$ and higher $\left(90{ }^{\circ} \mathrm{C}\right)$ solution temperatures than $70{ }^{\circ} \mathrm{C}$, a slight blueshift of PL was observed, as indicated in Fig. 1 (d)-(f). Recently, our group [15] reported that the blueshift of PL spectra was closely related to local chemical inhomogeneity of $\mathrm{MAPbI}_{3-\mathrm{x}} \mathrm{Cl}_{\mathrm{x}}$ that strongly depended on grain sizes and positions of perovskites. For instance, the chlorine $(\mathrm{Cl})$ mainly presented inside the grain interiors in which a higher atomic percentage of $\mathrm{Cl}$ was found with large grain perovskites while a negligible amount of $\mathrm{Cl}$ existed for smaller grain perovskites. Remarkably, it is also found that the grain boundaries were composed of the non-stoichiometric $\mathrm{CH}_{3} \mathrm{NH}_{3} \mathrm{PbI}_{\mathrm{x}}$ or $\mathrm{PbI}_{\mathrm{x}}$, which were characterized by an absence of chloride, a relatively high content of oxygen and a high density of iodide vacancies. In addition, two-dimensional (2D) PL mapping revealed larger optical bandgap 
of $\mathrm{CH}_{3} \mathrm{NH}_{3} \mathrm{PbI}_{\mathrm{x}}$ or $\mathrm{PbI}_{\mathrm{x}}$ at the grain boundaries than that of $\mathrm{CH}_{3} \mathrm{NH}_{3} \mathrm{PbI}_{\mathrm{x}-3} \mathrm{Cl}_{\mathrm{x}}$ at the grain interiors. Therefore, the blueshift of PL spectra of perovskite films can be attributed to the higher content of non-stoichiometric components. To verity this, PL spectra of perovskite films were deconvoluted using Gaussian functions [16], denoted with red and blue curves that were distinguished as ordered and disordered crystallinities as shown Fig. 1(d)-(f). It was found that the ratios of disordered to ordered phase were 1:1.03, 1:2.16, and 1:1.40 for solution temperatures of 40,70 and $90{ }^{\circ} \mathrm{C}$, respectively.

To quantitatively determine the concentration of trap states, excitation-dependent PL measurements $[17,18]$ were used in which the initial photogenerated charge carrier densities $\mathrm{n}(0)$ is given by

$$
\mathrm{n}(0)=\sum_{i} N_{t}^{i}(0)\left(1-\exp \left(-\frac{a_{i} \tau_{0} I_{P L}}{k}\right)\right)+\frac{I_{P L}}{k}
$$

where $\mathrm{I}_{\mathrm{PL}}$ is the integrated $\mathrm{PL}$ intensity which relates to the carrier density by $\mathrm{I}_{P L}=$ $k \int_{0}^{\infty} n_{c}(t) / \tau_{0} d t$. Also, $k$ is a constant for a given sample, $\tau_{0}$ is the PL lifetime, $N_{t}^{i}$ is the initial unfilled trap state density and $a_{i}$ is the product of the trap cross section and the carrier velocity. Thus, different types of traps such as surface $\left(N_{t}^{S}\right)$ and bulk $\left(N_{t}^{B}\right)$ traps can be extracted from an equation 1. Recently, this approach has been adapted to calculate trap state densities for perovskite films $[17,18]$. Fig. 2 shows the best-fitting of excitation-dependent PL and the results are listed in Table 1. We found that bulk trap densities were $1.1 \times 10^{16}, 3.2 \times 10^{15}$, and $7.3 \times 10^{15}$ $\mathrm{cm}^{-3}$ while surface trap densities were $1.1 \times 10^{17}, 7.7 \times 10^{16}$ and $1.2 \times 10^{17} \mathrm{~cm}^{-3}$ for perovskite thin films prepared with different solution temperatures of 40,70 and $90{ }^{\circ} \mathrm{C}$. Note such concentrations of trap states are in good agreements with previously reported values $[17,18]$. 
Thus, our calculation suggests that the perovskite films prepared with solution temperatures of $70{ }^{\circ} \mathrm{C}$ resulted in higher crystalline quality with a lower density of defects.

To investigate the impacts of perovskite solution temperatures on recombination dynamics of photogenerated charge carriers, we conducted time-resolved emission spectra (TRES) that probe the relaxation process of charge carriers of perovskites films, as shown in Fig. 3. Interestingly, all samples showed spectral dependent lifetime decays which might originate from local defects and band tail states [19]. Recent studies have shown the existence of significant spatial variations in PL intensity and carrier lifetime of perovskites [20]. Such results are interpreted as the contiguous variations of chemical and crystalline disorders across perovskite grains that produce local defects and band tail states. Particularly, the excitons weakly localized in band tail states involve relaxation processes from excited states to localized band tail states, resulting in longer lifetimes of photo-generated charge carriers. This suggests that the measurement of a spectral dependence of PL decays allows one to detect the presence of band tail structures and the excitonic transitions. Therefore, the elongated lifetimes at longer wavelengths could be attributed to the localized excitons in which the longer lifetime at the longer wavelength was due to the involvement of relaxation of excited charge carriers to localized states or band tail states [19]. Fig. 3 shows different degrees of spectral dependent lifetimes of perovskite films with different solution temperatures. Particularly, perovskite films prepared with solution temperatures of 40 and $90{ }^{\circ} \mathrm{C}$ showed a relatively weak spectral dependence of PL decays. On the contrary, the strong spectral dependence of PL decays of perovskite with solution temperatures of $70{ }^{\circ} \mathrm{C}$ was observed and strongly skewed to the lower energy side. This suggests that transient decays occur via localized channels at the longer wavelengths. 
To further understand the relaxation kinetics of photo-generated charge carriers correlated to defect states of perovskite thin films, excitation-power dependent PL was undertaken and shown in Fig.4. It is worthwhile noting that the PL intensity $\mathbf{I}_{\mathbf{P L}}$ has a relationship with the power $\mathbf{P}$ of the excitation laser as $\mathrm{I}_{\mathrm{PL}} \propto \mathrm{P}^{\beta}$, where $\beta$ is the power index [21,22]. When the value of $\beta$ is less than unity, free-to-bound and donor-acceptor pair (DAP) recombination will dominate while values in the range of $1<\beta<2$ indicate the excitonlike transition. Notably, perovskite films prepared with solution temperatures at 40 and 90 ${ }^{\circ} \mathrm{C}$ exhibited power index values of $\beta=0.67$ and 0.98 at lower power density $(<80$ $\mathrm{mW} / \mathrm{cm}^{2}$ ). This indicates that defect-mediated, nonradiative recombination processes will dominate. In contrast, the exciton-like transition was found for a perovskite film prepared at solution temperatures of $70{ }^{\circ} \mathrm{C}$ which exhibited a super linear power dependence with an exponent $\beta=1.36$. Remarkably, with increased power densities $\left(>80 \mathrm{~mW} / \mathrm{cm}^{2}\right)$ all samples showed the power index values in the range of $1<\beta<2$ in which exciton-like transitions start to dominate. Similar observation [23] was reported in which at higher power densities the exciton-like transitions in perovskite thin films start to dominate due to the gradual saturation of non-radiative recombination centres.

Based on our observations, the charge carrier relaxation mechanism can be explained for observed spectral dependence lifetime decays and illustrated in Fig.5. As reported, the contiguous variations of chemical and crystalline disorders across perovskite grains are expected. In this case, local disorders will form localized energetic states at which the excitons will be formed and be manifested as the spectral dependent decays of charge carriers. As observed, perovskite films fabricated with solution temperatures of $70{ }^{\circ} \mathrm{C}$ will 
have higher crystalline quality. However, it is anticipated that perovskite films still contain local crystalline disorders that create the band tail states. In this case, the excited photo-generated charge carriers will relax to lower energy band tail states and form localized excitons, as shown in Fig. 5(a). Therefore, it is expected that the exciton-like transition will dominate and show the strong spectral dependence of PL decays. On the contrary, perovskites prepared with lower $\left(40{ }^{\circ} \mathrm{C}\right)$ solution temperatures will contain defects at which the photogenerated charge carriers will be instantaneously trapped before forming the localized excitons, as shown in Fig. 5(b). We believe that such trap states for perovskite films prepared at precursor solution temperatures of $40^{\circ} \mathrm{C}$ led to trap-mediated transition rather than exciton-like transition, resulting in the weak spectral dependence PL decays as evidenced in Fig. 3 (a).

To investigate the effect of solution temperatures on the photovoltaic performance, hybrid perovskite solar cells were fabricated with the device structure of FTO/PEDOT: PSS/ $\mathrm{CH}_{3} \mathrm{NH}_{3} \mathrm{PbI}_{3-\mathrm{x}} \mathrm{Cl}_{\mathrm{x}} / \mathrm{PCBM} / \mathrm{Ag}$ (See Fig. 6(a)). Fig. 6(b) depicts the current-voltage characteristics of solar cells with different perovskite solution temperatures and resultant photovoltaic parameters for perovskite solar cells are also listed in Table 2. In case of lower solution temperatures $\left(40{ }^{\circ} \mathrm{C}\right)$, the average efficiency is around $8.8 \%$ while higher solution temperatures of 70 and $90{ }^{\circ} \mathrm{C}$ led to higher efficiencies of $12.6 \%$ and $10.9 \%$, respectively. An inset confirms that the better performance of perovskite solar cells can be achieved by the perovskite solution temperature around $70{ }^{\circ} \mathrm{C}$. It seems like that the difference in the crystal quality influenced the short-circuit current density $\left(\mathrm{J}_{\mathrm{SC}}\right)$, fill factor $(\mathrm{FF})$, and open-circuit voltage $\left(\mathrm{V}_{\mathrm{OC}}\right)$ of the perovskite solar cells. Indeed, as shown 
in UV-VIS measurement, a better absorption was observed for perovskite film with solution temperatures of $70{ }^{\circ} \mathrm{C}$ that can be attributed to the higher crystalline quality as observed from PL. Since the $\mathrm{V}_{\mathrm{OC}}$ is closely related to interface charge extraction efficiencies, PL quenching was measured for perovskite layers on hole extraction layer PEDOT: PSS. Fig. 6(d) shows the PL spectra of $\mathrm{CH}_{3} \mathrm{NH}_{3} \mathrm{PbI}_{3}$ ${ }_{\mathrm{x}} \mathrm{Cl}_{\mathrm{x}} / \mathrm{PEDOT}$ :PSS/FTO/glass for PL quenching studies. It should be noted that the relatively low PL spectra indicate that the effective charge transfer from photoactive layers to PEDOT: PSS hole transfer layer. The lowest PL intensity was observed for perovskite films prepared at solution temperatures of $70{ }^{\circ} \mathrm{C}$ which indicates the excellent charge extraction efficiency. On the contrary, the poorest charge extraction efficiency was observed for a perovskite film prepared at solution temperatures at $40{ }^{\circ} \mathrm{C}$. This might be attributed to a higher density of defects that slow down the extraction process of photogenerated charge carriers. It is noteworthy that the perovskite film with solution temperatures of $40{ }^{\circ} \mathrm{C}$ showed a larger blue-shift of PL spectra and a higher density of defects in films.

\section{Conclusion}

We have investigated the effect of precursor solution temperatures on the perovskite film and solar cells. It is found that when perovskite films were prepared with lower or higher temperatures than $70{ }^{\circ} \mathrm{C}$, the defect-mediated recombination processes were dominant. Higher trap rates of photo-generated charge carriers were observed which was possibly related to the lower values of $\mathrm{J}_{\mathrm{SC}}, \mathrm{FF}$ and $\mathrm{V}_{\mathrm{OC}}$. On the contrary, when perovskite films were prepared with the solution temperature around $70{ }^{\circ} \mathrm{C}$, a low density of defects was observed and the exciton-like 
transition dominated. For perovskite solar cells, better photovoltaic performance of perovskite solar cells was observed when prepared with the precursor temperature around $70{ }^{\circ} \mathrm{C}$.

Acknowledgements This work was partially supported by the National Science Foundation under projects (1428298 and 1547771). 


\section{Table captions}

Table 1. Surface and bulk trap densities of perovskite samples

Table 2. Photovoltaic parameters of perovskite solar cells fabricated with different perovskite solution temperatures 


\section{Table 1.}

\begin{tabular}{ccc}
\hline \hline & Surface trap densities $\left(\mathbf{c m}^{-3}\right)$ & Bulk trap densities $\left(\mathbf{c m}^{-\mathbf{3}}\right)$ \\
$\mathbf{4 0}{ }^{\circ} \mathrm{C}$ & $1.1 \times 10^{17}$ & $1.1 \times 10^{16}$ \\
$\mathbf{7 0} \mathbf{C}$ & $7.7 \times 10^{16}$ & $3.2 \times 10^{15}$ \\
$\mathbf{9 0}^{\circ} \mathrm{C}$ & $1.2 \times 10^{17}$ & $7.3 \times 10^{15}$ \\
\hline
\end{tabular}

Table 2.

\begin{tabular}{ccccc}
\hline \hline & $\mathbf{J}_{\mathrm{SC}}$ & $\mathbf{V}_{\mathbf{O C}}$ & $\mathbf{F F}$ & Efficiency \\
& $\left(\mathbf{m A} / \mathbf{c m}^{\mathbf{2}}\right)$ & $(\mathbf{V})$ & & $(\%)$ \\
$\mathbf{4 0}^{\circ} \mathbf{C}$ & 16.77 & 0.88 & 59.76 & 8.82 \\
$\mathbf{7 0}{ }^{\circ} \mathbf{C}$ & 21.93 & 0.97 & 59.04 & 12.56 \\
$\mathbf{9 0}^{\circ} \mathbf{C}$ & 20.36 & 0.93 & 57.57 & 10.9 \\
\hline \hline
\end{tabular}




\section{Figure captions}

Fig.1. Microscopic images of perovskite thin films with different perovskite solution temperatures of (a) 40, (b) 70 and (c) $90{ }^{\circ} \mathrm{C}$. PL spectra with solution temperatures of (d) 40, (e) 70 and (f) $90{ }^{\circ} \mathrm{C}$ were deconvoluted and denoted with red and blue curves that were distinguished as ordered and disordered crystallinities. The ratios of disordered to ordered phases were $1: 1.03,1: 2.16$, and 1:1.40 for solution temperatures of 40,70 and 90 ${ }^{\circ} \mathrm{C}$, respectively.

Fig.2. Photogenerated charge carriers vs. PL intensities of perovskite samples prepared with different perovskite precursor temperatures of 40,70 and $90{ }^{\circ} \mathrm{C}$. Dotted lines are best-fitted data using an equation 1.

Fig. 3. Spectral dependent lifetime decays for perovskite thin films prepared with perovskite solution temperatures of (a) $40^{\circ} \mathrm{C}$, (b) $70^{\circ} \mathrm{C}$, and (c) $90^{\circ} \mathrm{C}$.

Fig. 4. Excitation-power dependent PL measurements fitted by a power-function $\mathrm{I}_{\mathrm{PL}} \propto \mathrm{P}^{\beta}$ with the power index $\beta$. The inset shows the power index values for lower $\left(<80 \mathrm{~mW} / \mathrm{cm}^{2}\right)$ and higher power $\left(>80 \mathrm{mV} / \mathrm{cm}^{2}\right)$ densities.

Fig.5. Schematics of recombination dynamics of photogenerated charge carriers showing (a) exciton-like transition with a lower density of defects and (b) defect-mediated transition with a higher density of defects 
Fig.6. (a) SEM image of FTO/PEDOT:PSS/MAPbI ${ }_{3-\mathrm{x}} \mathrm{Cl}_{\mathrm{x}} / \mathrm{PCBM} / \mathrm{Ag}$ (b) current-voltage characterization of perovskite solar cells, (c) UV-VIS measurement of perovskite thin film on glass, and (d) PL spectra for perovskite/PEDOT: PSS/glass. An inset shows the efficiency of perovskite solar cells fabricated with other perovskite solution temperatures. 

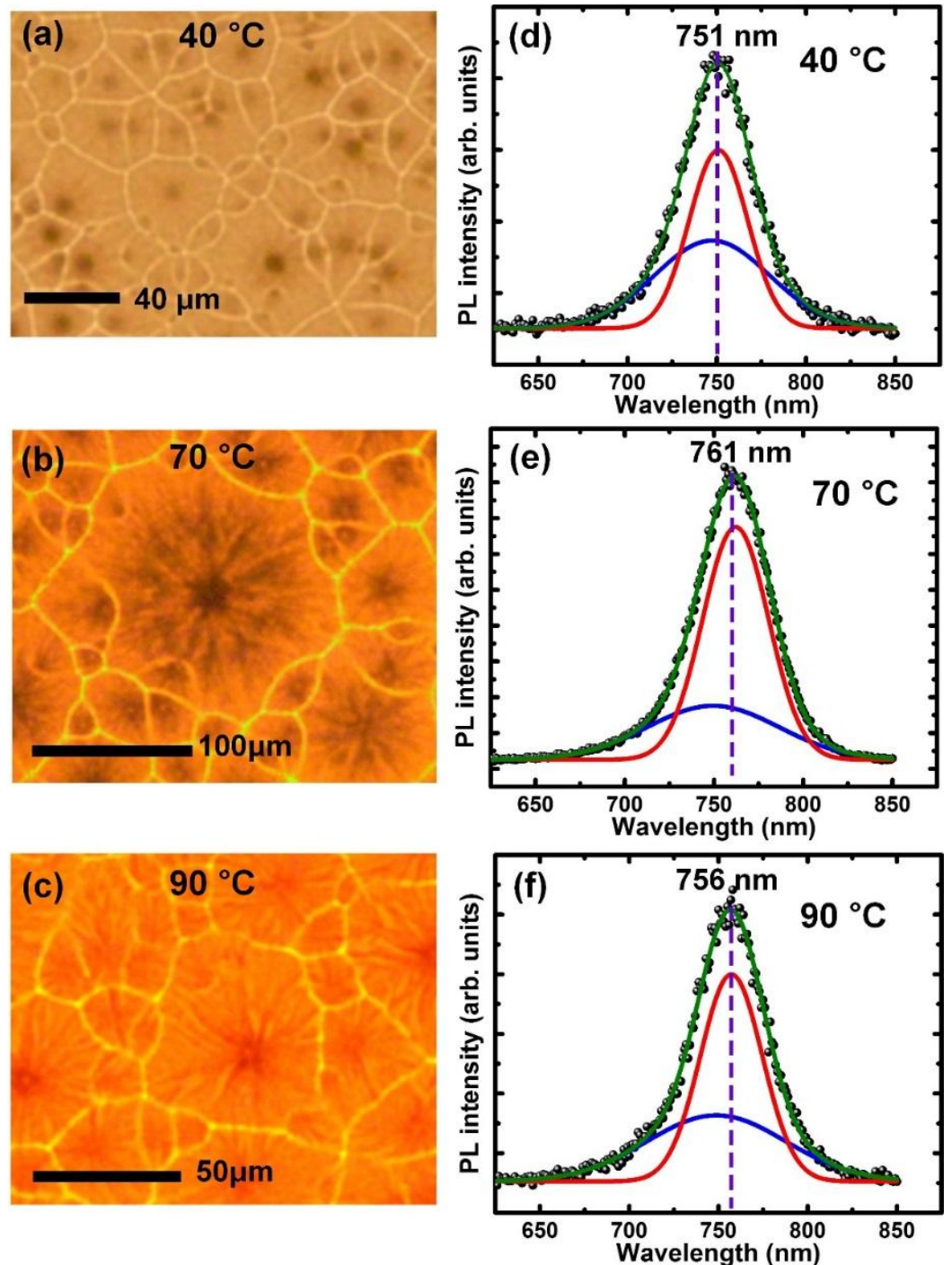

Figure 1. 


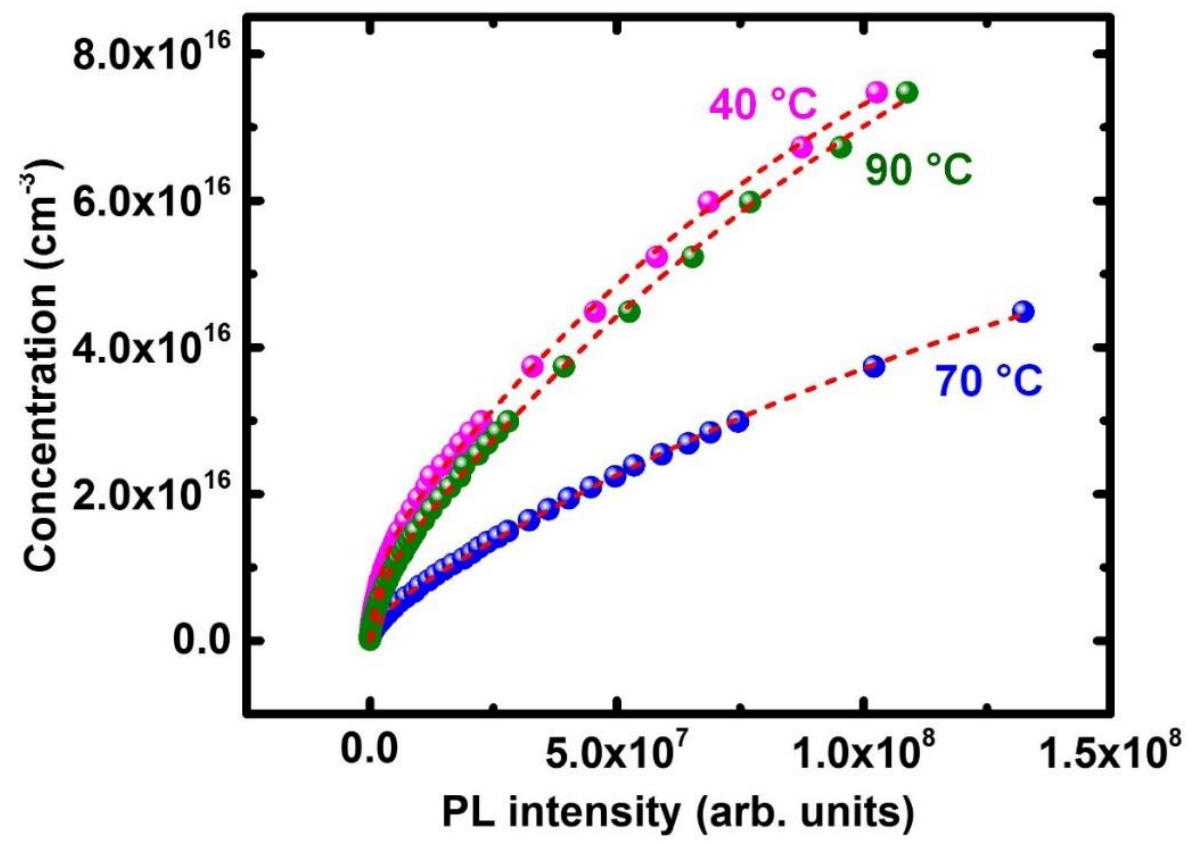

Figure 2 

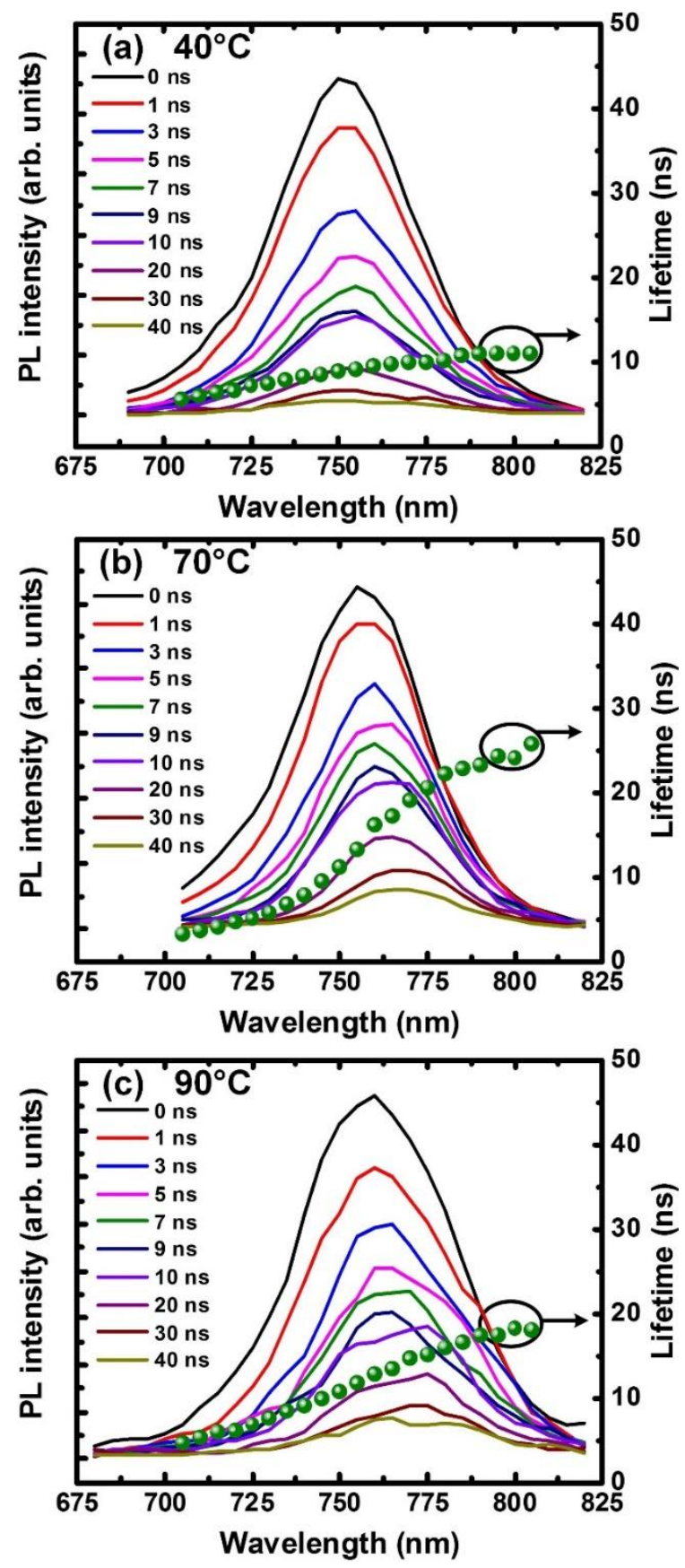

Figure 3. 


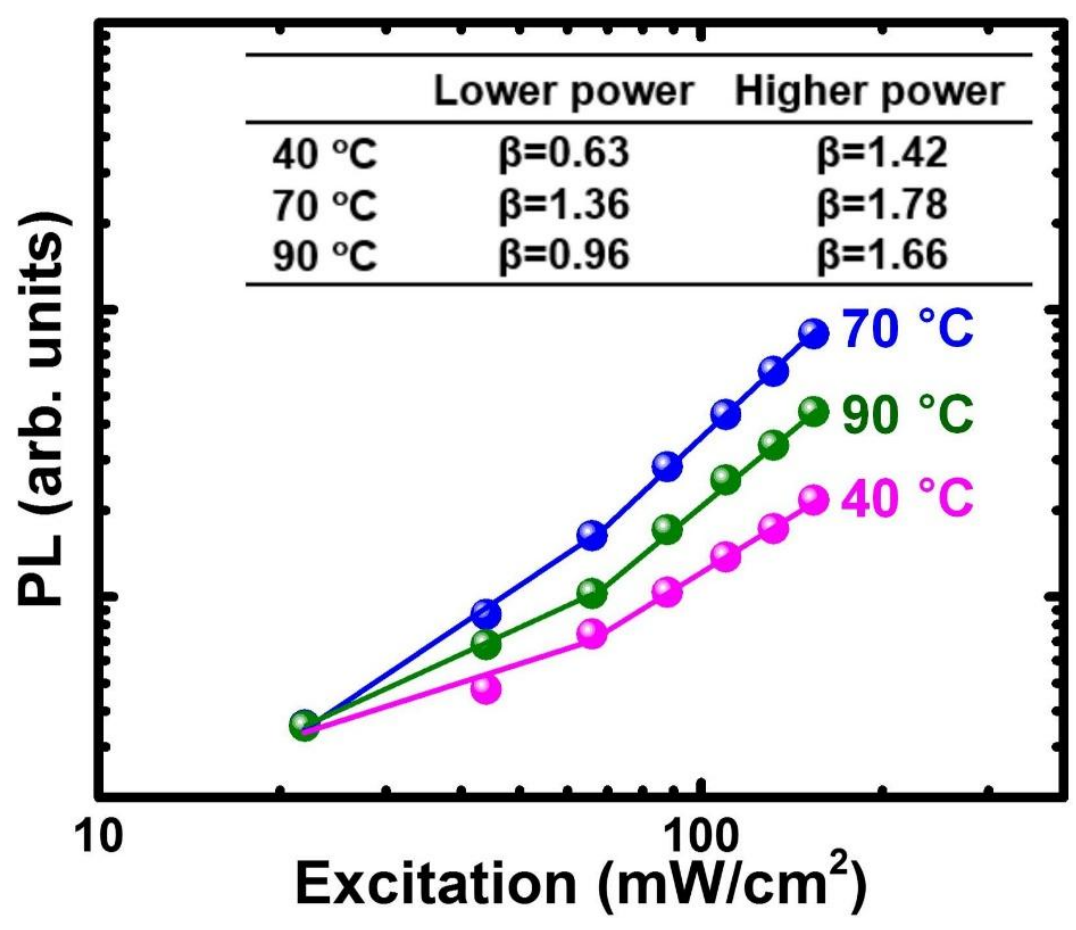

Figure 4. 

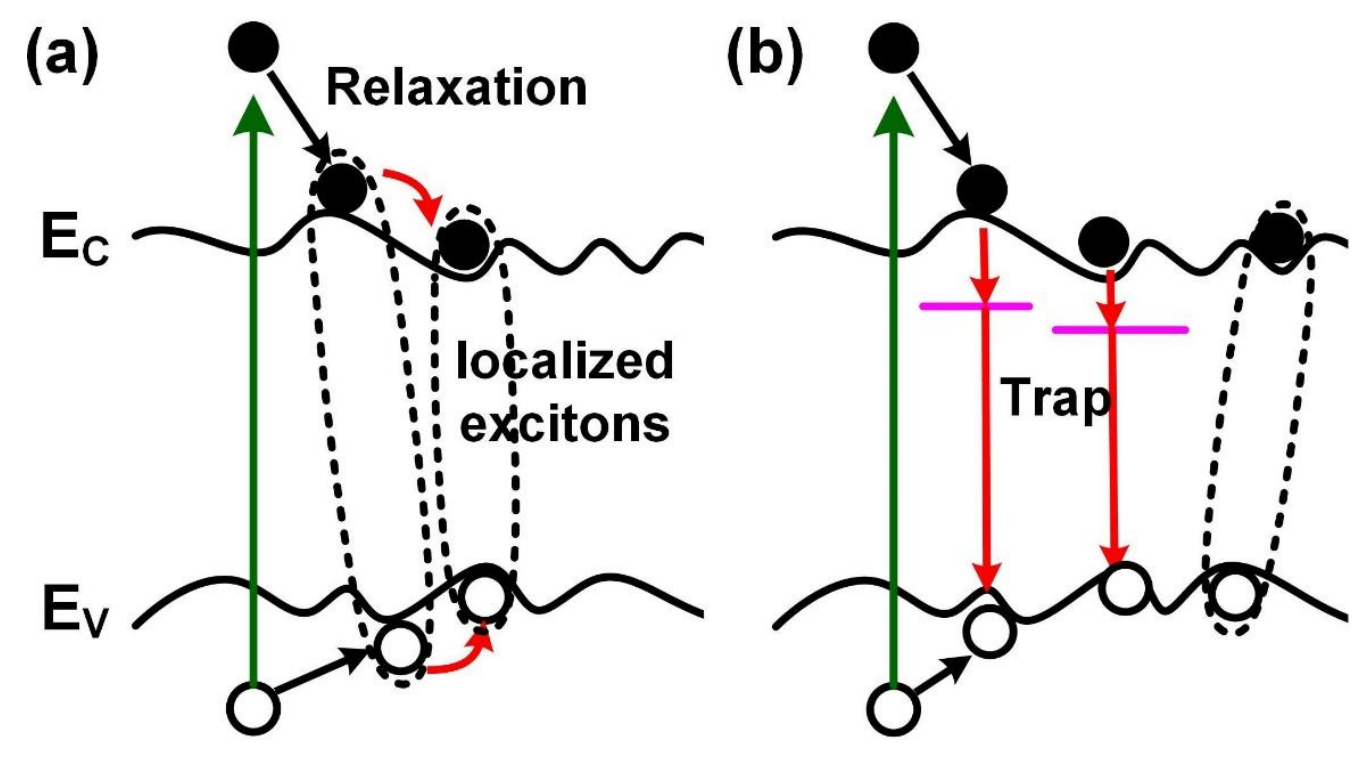

Figure 5. 

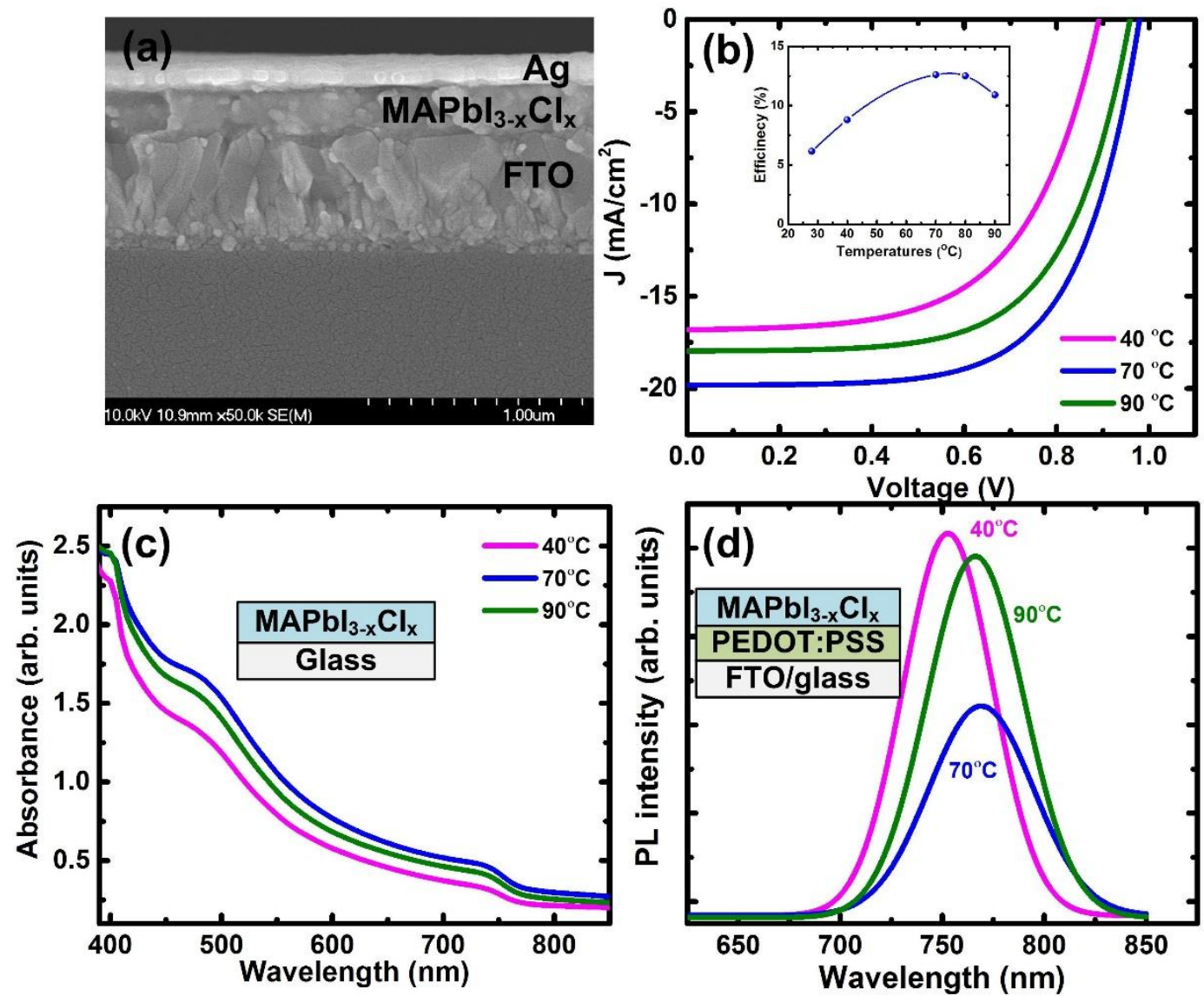

Figure 6. 


\section{References}

[1] M. M. Lee, J. Teuscher, T. Miyasaka, T. N. Murakami, H. J. Snaith, Efficient Hybrid Solar Cells Based on Meso-Superstructured Organometal Halide Perovskites, Science 338 (2012) 643-647.

[2] J. Burschka, N. Pellet, S.-J. Moon, R. Humphry-Baker, P. Gao, M. K. Nazeeruddin, M. Gr“atzel, Sequential deposition as a route to high-performance perovskite-sensitized solar cells, Nature 499 (2013) 316- 319.

[3] H. Zhou, Q. Chen, G. Li, S. Luo, T.-b. Song, H.-S. Duan, Z. Hong, J. You, Y. Liu, Y. Yang, Interface engineering of highly efficient perovskite solar cells, Science 345 (2014) 542-546.

[4] N. J. Jeon, H.G. Lee, Y.C. Kim, J. Seo, J.H. Noh, J. Lee, S. I. Seok, o-Methoxy Substituents in Spiro-OMeTAD for Efficient Inorganic-Organic Hybrid Perovskite Solar Cells, J. Am. Chem. Soc. 136 (2014) 7837- 7840.

[5] N. G. Park, Perovskite solar cells: an emerging photovoltaic technology, Materials today 18 (2015) 65-72. 
[6] C.C. Stoumpos, D.C. Malliakas, M.G. Kanatzidis, Semiconducting tin and lead iodide perovskites with organic cations: phase transitions, high mobilities, and near-infrared photoluminescent properties, Inorg. Chem. 52 (2013) 9019-9038.

[7] M. Xiao, F. Huang, W. Huang, Y. Dkhissi, Y. Zhu, J. Etheridge, A. Gray-Weale, U. Bach, Y. B. Cheng, L. Spiccia, Angew. A Fast Deposition-Crystallization Procedure for Highly Efficient Lead Iodide Perovskite Thin-Film Solar Cells, Chem. 53 (2014) 9898-9903.

[8] W. Nie, H. Tsai, R. Asadpour, J.-C. Blancon, A. J. Neukirch, G. Gupta, J. J. Crochet, M. Chhowalla, S. Tretiak, M. A. Alam, H.-L. Wang, A. D. Mohite, High-efficiency solution-processed perovskite solar cells with millimeter-scale grains, Science 347 (2015) 522-525.

[9] J. Burschka, N. Pellet, S.J. Moon, T. Humphry-Baker, P. Gao, M.K. Nazeeruddin, M. Grätzel, Sequential deposition as a route to high-performance perovskite-sensitized solar cells, Nature 499 (2013) 316-319.

[10] D. Bi, S.J. Moon, L. Häggman, G.Boschloo, L. Yang, E.M. Johansson, A. Hagfeldt, Using a two-step deposition technique to prepare perovskite $\left(\mathrm{CH}_{3} \mathrm{NH}_{3} \mathrm{PbI}_{3}\right)$ for thin film solar cells based on $\mathrm{ZrO}_{2}$ and $\mathrm{TiO}_{2}$ mesostructures, Rsc Advances. 3 (2013) 18762-18766.

[11] M.M. Lee, J. Teuscher, T. Miyasaka, T.N. Murakami, H.J. Snaith, Efficient hybrid solar cells based on meso-superstructured organometal halide perovskites, Science 338 (2012) 643-647.

[12] D. Khatiwada, S. Venkatesan, N. Adhikari, A. Dubey, A. F. Mitul, L. Mohammad, A. Iefanova, S. B. Darling, Q. Qiao, Efficient Perovskite Solar Cells by Temperature Control in 
Single and Mixed Halide Precursor Solutions and Films, J. Phys. Chem. C 119 (2015) $25747-25753$.

[13] C. Bi1, Q. Wang, Y. Shao, Y. Yuan, Z. Xiao, J. Huang, Non-wetting surface-driven high-aspect-ratio crystalline grain growth for efficient hybrid perovskite solar cells, Nat. Communication 6 (2015) 7747.

[14] W. Nie, H. Tsai, R. Asadpour, J.-C. Blancon, A. J. Neukirch, G. Gupta, J. J. Crochet, M. Chhowalla, S. Tretiak, M. A. Alam, H.-L. Wang, A. D. Mohite, High-efficiency solution-processed perovskite solar cells with millimeter-scale grains, Science. 347 (2015) 522-525.

[15] G. Namkoong, H. J. Jeong, A. Mamun, H. Byun, D. Demuth, M.S. Jeong, Chemically, spatially, and temporally resolved 2D mapping study for the role of grain interiors and grain boundaries of organic-inorganic lead halide perovskites, Sol. Energy Mat. Sol. Cells 155 (2016) 134-140.

[16] B.-w. Park, S. M. Jain, X. Zhang, A. Hagfeldt, G. Boschloo, T. Edvinsson, Resonance Raman and Excitation Energy Dependent Charge Transfer mechanism in Halide-Substituted Hybrid Perovskite Solar Cells, ACS Nano 9 (2015) 2088-2101.

[17] G. Xing, N. Mathews, S. S. Lim, N. Yantara, X. Liu, S. Dharani, M. Grätzel, S. Mhaisalkar, T. C. Sum, Low-temperature solution-processed wavelength-tunable perovskites for lasing, Nat. Materials 13 (2014) 476-480.

[18] W. Peng, B. Anand, L. Liu, S. Sampat, B. E. Bearden, A. V. Malko, Y. J. Chabal, Influence of growth temperature on bulk and surface defects in hybrid lead halide perovskite films, Nanoscale 8 (2016) 1627-1634. 
[19] H. He, Q. Yu, H. Li, J. Li, J. Si, Y. Jin, N. Wang, J. Wang, J. He, X. Wang, Y. Zhang, Z. Ye, Exciton localization in solution-processed organolead trihalide perovskites, Nat. Comm. 7 (2016) 10896.

[20] D. W. deQuilettes, S. W. Vorpah, S. W. Stranks, H. Nagaoka, G.E. Eperon, M.E. Ziffer, H.J. Snaith, D.S. Ginger, Impact of microstructure on local carrier lifetime in perovskite solar cells, Science 348 (2015) 683-686.

[21] T. Schmidt, K. Lischka, W. Zulehner, Excitation-power dependence of the nearband-edge photoluminescence of semiconductors, Phys. Review B 45 (1992) 8989.

[22] H. Shibata, M. Sakai, A.Yamada, K. Matsubara, K. Sakurai, H. Tampo, S. Niki, Excitation-power dependence of free exciton photoluminescence of semiconductors, Jap. J. Appl. Phys. 44, (2005) 6113.

[23] V. D’Innocenzo, G.Grancini1, M. J.P. Alcocer, A. R. S. Kandada, S. D. Stranks, M. M. Lee, G. Lanzani, H. J. Snaith, A. Petrozza, Excitons versus free charges in organo-lead tri-halide perovskites, Nat. Communiation 5 (2014) 3586. 
Graphic abstract
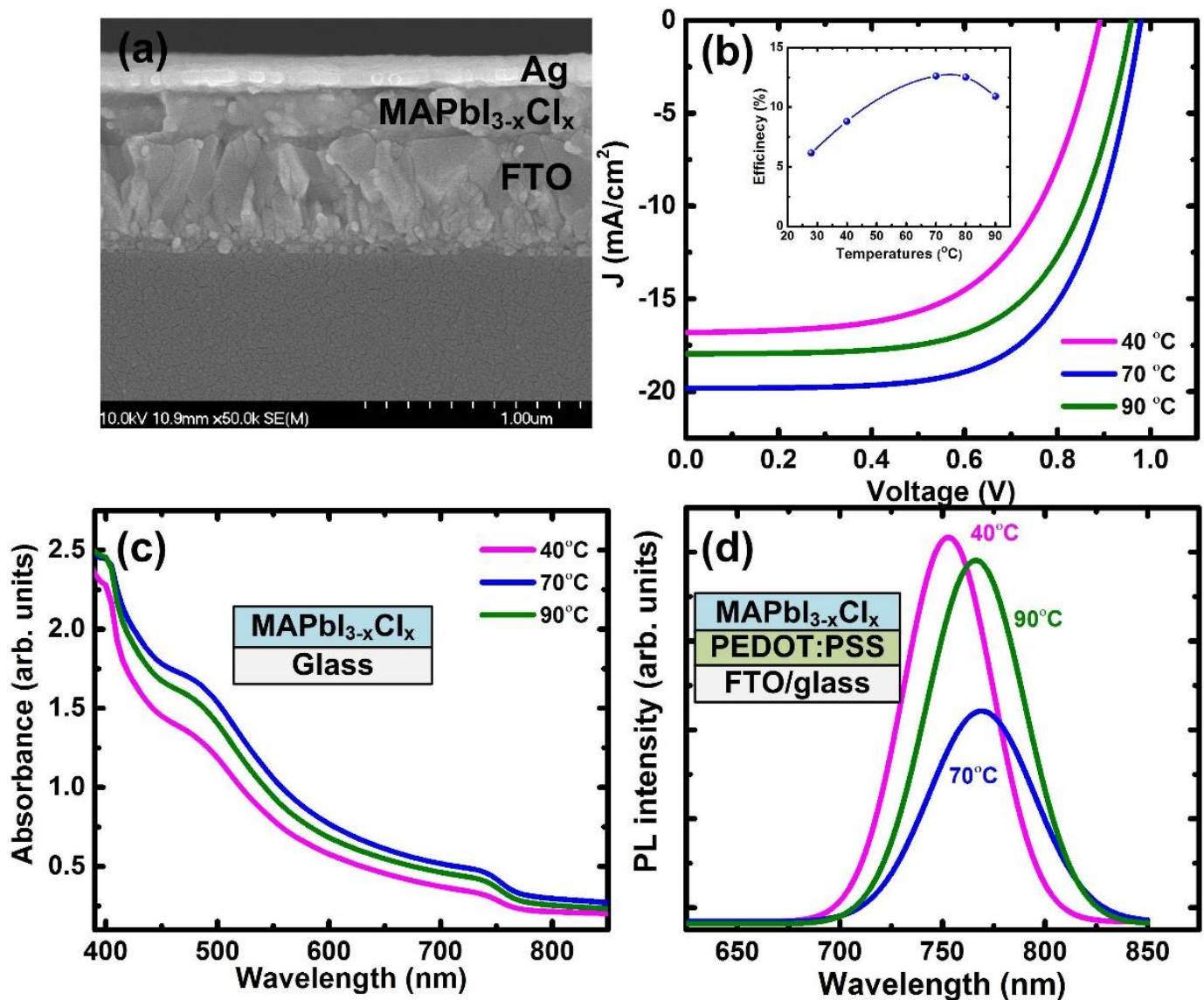